\title{
Successful air reduction in a patient with recurrent intussusception with a history of ileocecectomy for ileocolic intussusception
}

\author{
Tae Gyoung Lee, Eun Yi Lee, Cheol Hwan So, Seung Taek Yu \\ Department of Pediatrics, Wonkwang University School of Medicine, Iksan, Korea
}

Received September 16, 2019

Revised October 2, 2019

Accepted October 11, 2019

Corresponding author

Seung Taek Yu

Department of Pediatrics,

Wonkwang University School of

Medicine, 460, Iksan-daero, Iksan

54538, Korea

Tel: +82-63-859-1510,

Fax: +82-63-853-3670

E-mail:yudoc@wku.ac.kr

ORCID:

http://orcid.org/0000-0001-9744-5548

\begin{abstract}
Intussusception is the most common cause of intestinal obstruction in children younger than 2 years. Despite successful reduction, recurrence of intussusception may occur. Recurrence after intestinal resection rarely occurs. We present a case of recurrent intussusception in a patient with a history of ileocecectomy for ileocolic intussusception. The patient was diagnosed with ileocolic intussusception with peritonitis at the age of 5 months, which was managed with ileocecectomy. At 9 months postoperatively, the patient presented with hematochezia. Ultrasound imaging showed ileocolic intussusception; thus, we performed air reduction, which resulted in successful outcomes. No recurrence has occurred at three years postoperatively.
\end{abstract}

Keywords: Intussusception; Recurrence; Intestinal obstruction; Pediatrics

\section{INTRODUCTION}

Intussusception is a condition in which a portion of the intestine enters into another adjacent intestine [1], and it is the most common cause of intestinal obstruction in children younger than 2 years. Its common symptoms in infants and young children include cyclic irritability, abdominal pain, vomiting, bloody mucoid stool, and palpable mass. Intussusception is an emergent disease that can lead to complications, such as ischemia of the intestinal wall, intestinal necrosis, perforation, peritonitis, shock, and sepsis when early diagnosis and treatment are delayed [2]. In the absence of any contraindications, its primary management is non-sur- gical decompression, such as air reduction, barium reduction, and hydrostatic pressure reduction. In cases wherein these reduction procedures failed, frequent recurrences have occurred after successful reduction, a pathologic trigger point was identified, or there is a contraindication to non-surgical reduction, surgical reduction is then necessary $[1,3]$. Despite the successful reduction, recurrence of intussusception may occur, which was reported to be found in approximately $8-15 \%$ and 2-5\% of non-surgical and surgical reduction cases, respectively (after barium enema, 4-20\%; after hydrostatic decompression, 10-15\%) [1,4-6]. The recurrence rate is high in children with underlying lesions such as Meckel's diverticulum, intestinal polyp, duplication 
cyst, tumor-like lymphosarcoma, band, Henoch-Schonlein purpura, and cystic fibrosis. However, most of them are idiopathic; thus, several studies have investigated the cause and predictive factors of recurrence [1,6]. In most studies, no recurrence was found after intestinal resection [5,6]. However, in this paper, we report a rare case of recurrent intussusception in a pediatric patient with a history of ileocecectomy for ileocolic intussusception. We also present a literature review of this condition.

\section{CASE REPORT}

A 15-month-old male infant presented with bloody mucoid stool occurring on the day of hospital visit. As an infant who had been in good health, he had three more dilute feces than usual in the morning of his hospital visit. In the afternoon of the same day, dark to bright reddish mucoid stool with blood clot was noted; thus, he was brought to the emergency room.

He was born through cesarean section at 35 weeks, and birth weight was 2,360 g. At 5 months of age, he visited the emergency room of our institution because of vomiting, diarrhea, lethargy, poor feeding, and decreased urination. Abdomen X-ray showed distended small bowel (Fig. 1A). He was diagnosed as having ileocolic intussusception with peritonitis, as seen in the abdominal ultrasound (Fig. 1C); thus, he underwent surgical resection, ileocecectomy (Fig. 2), and ileocolostomy. Follow up X-ray after operation showed normalized gas pattern of bowels (Fig. 1B).

At his hospital visit at 15 months of age, the patient weighed $9.3 \mathrm{~kg}\left(10^{\text {th }}-25^{\text {th }}\right.$ percentile) with a stable vital sign. He was alert and appeared relatively well. During physical examinations, the his bowel sound was decreased, the abdomen was soft and flat, and there was no tenderness or palpable mass.

Blood examinations revealed the following: total white blood cell count of $13,970 / \mathrm{mm}^{3}$, hemoglobin level of 12.3 $\mathrm{g} / \mathrm{dL}$, platelet count of $240,000 / \mathrm{mm}^{3}$, and erythrocyte sedimentation rate of $7 \mathrm{~mm} / \mathrm{h}$. In the electrolyte test, sodium level was $145 \mathrm{mEq} / \mathrm{L}$, potassium level was $4.7 \mathrm{mEq} / \mathrm{L}$, chloride level was $107 \mathrm{mEq} / \mathrm{L}$, and C-reactive protein level was $3.6 \mathrm{mg} / \mathrm{L}$. Results of the venous blood gas analysis showed $\mathrm{pH}$ of 7.38 , base excess of $-3.7 \mathrm{mM} / \mathrm{L}$, and bicarbonate level of $21.8 \mathrm{mM} / \mathrm{L}$. Stool occult blood was detected, but there
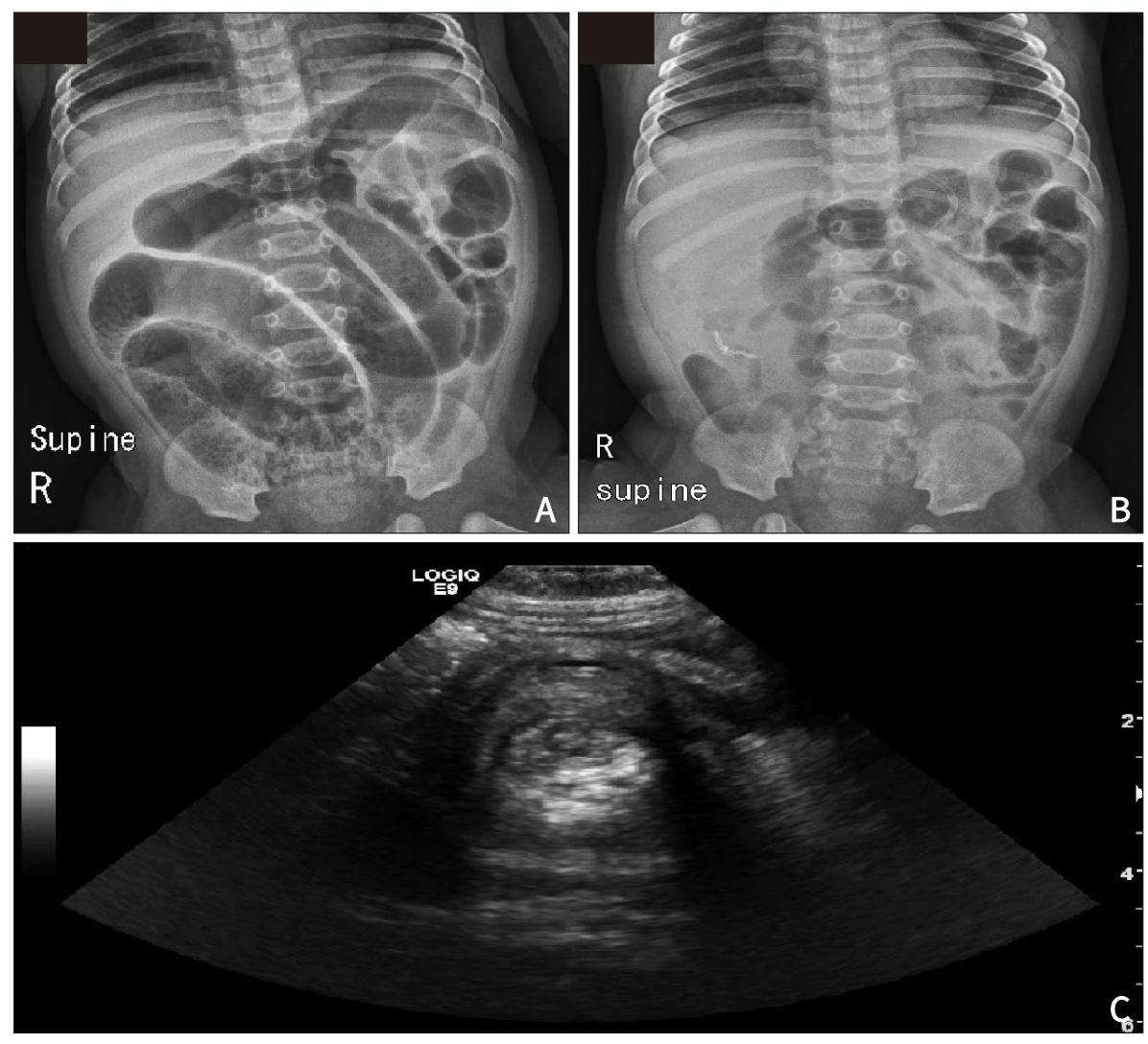

Fig. 1. X-ray image before the surgical resection $(A)$ showed severe gas distension of small bowel and $X$-ray image after the surgical resection (B) showed normalized gas pattern. Target like appearance (C) was observed in right mid abdominal area, indicating ileocecal intussusception. 
was no virus or bacteria noted in the stool culture and polymerase chain reaction.

There was mild gas distension of colon in the abdominal X-ray (Fig. 4A). In the abdominal ultrasonography, a target-signed ileocolic intussusception was noted in the right upper quadrant of abdomen, and no vascular decrease was found in Doppler (Fig. 3A, 3B). Furthermore, multiple

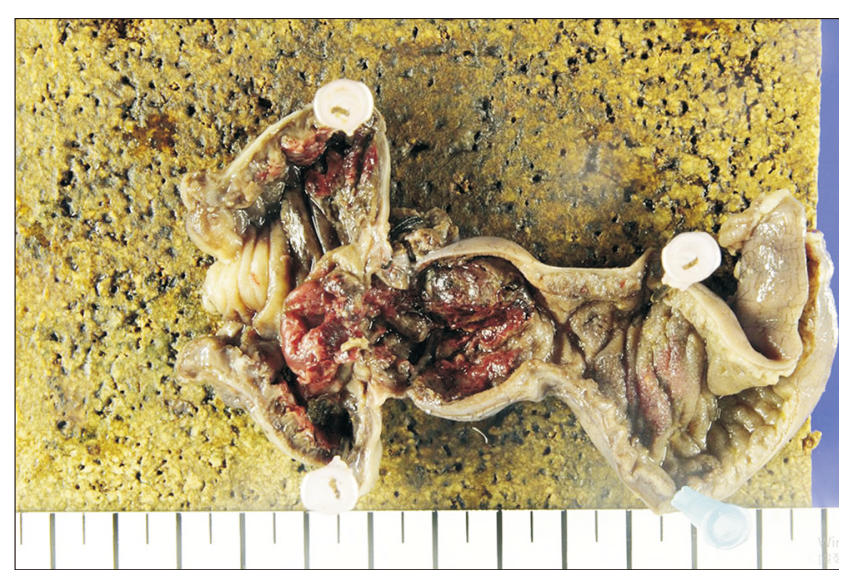

Fig. 2. This picture is a gross photo of the resection site after ileocecectomy during the first intussusception. enlarged mesenteric lymph nodes were noted (Fig. 3C, 3D), and the largest lymph node had a size of $8.1 \mathrm{~mm}$. Immediately after diagnosis, we conducted air reduction, which resulted in successful outcomes (Fig. 4B). We performed abdomen-pelvis computed tomography (CT) to confirm the pathologic leading point, and noted the presence of intestinal wall thickening at the anastomotic site adjacent to the surgical material, and no other lesions were found to be a pathologic lead.

After air reduction, the patient showed no clinical symptoms like abdominal pain, vomiting or hematochezia. On the third day of hospitalization, the stool occult blood test showed negative findings. He underwent conservative treatment and was discharged on the fifth hospital day. He is currently being followed up at our clinic and has been without any recurrence for three years.

\section{DISCUSSION}

Intussusception is a disease in which part of the intestine enters into the adjacent intestine [1], usually occurring in
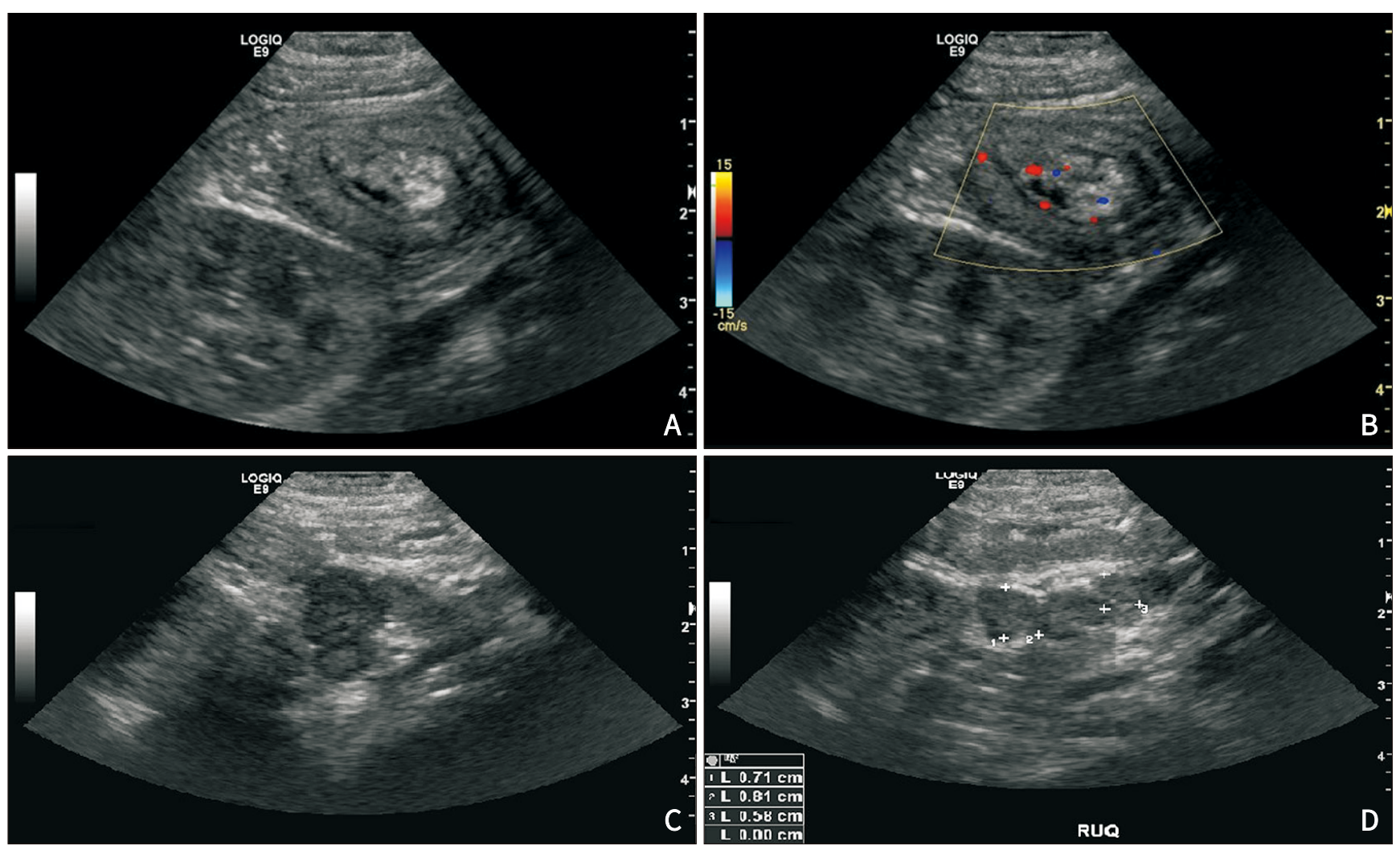

Fig. 3. Target sign (A, B) and multiple enlarged lymph nodes (C, D) were observed at right upper quadrant during the recurrent intussusception. 


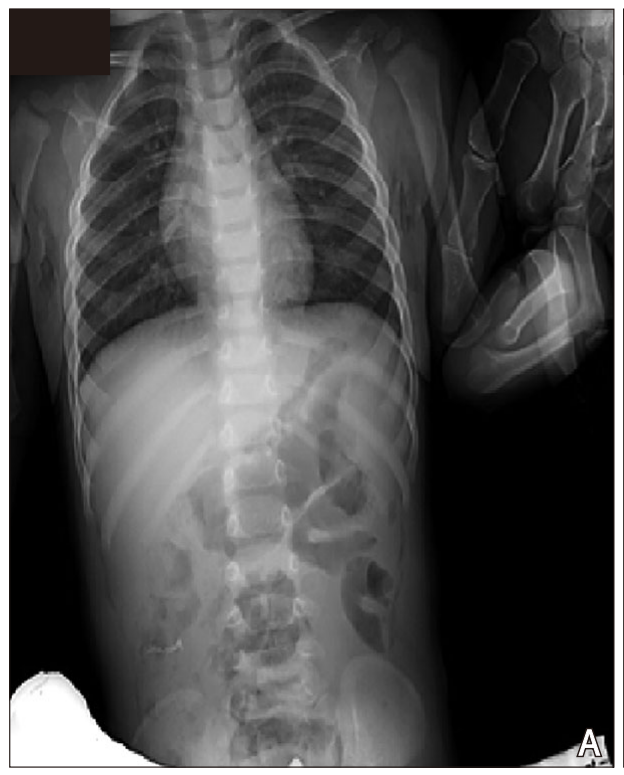

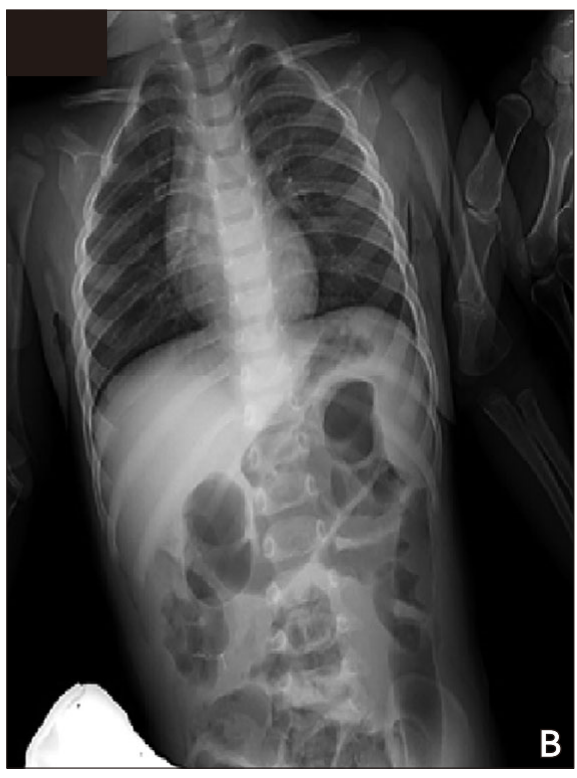

Fig. 4. X-ray image before the air reduction (A) showed mild gas distension of colon and $\mathrm{X}$-ray image after the air reduction $(\mathrm{B})$ showed air passage into the small bowels. boys aged between 3 months and 6 years, and $80 \%$ of cases occur in children younger than 2 years [1,7]. This disease may occur anywhere in the intestine, with the ileocolic type being the most common. Lee et al. and Yoo et al. have reported that $75.5 \%$ and $62 \%$ of cases, respectively, were of the ileocolic type [1,6].

Symptoms of intussusception in infants and children include cyclic irritability, abdominal pain, vomiting, bloody mucoid stool, and palpable mass on the abdomen. In the case of small intestinal intussusception, non-specific symptoms, such as abdominal pain, vomiting, irritability, and fever, are common, and its diagnosis and treatment are delayed, which increases the risk of complications such as intestinal wall ischemia, necrotizing changes, and perforation $[8,9]$.

The ultrasound is the most useful diagnostic tool for the diagnosis of intussusception, which would show a target sign or donut sign in the cross section or a pseudokidney sign in the longitudinal section. These signs indicate that the hyperechoic intussusceptum is at the center, and the edema of the wall of the intussuscipiens becomes hypoechoic and appears to be composed of the surrounding of the incarnation [10]. Sensitivity and specificity of ultrasound for diagnosing intussusception are reported to be $98-100 \%$ and $88-$ $100 \%$, respectively [11].

When a patient is diagnosed with intussusception, nonsurgical reductions such as air reduction, barium reduc- tion, and hydrostatic reduction are usually performed $[1,3]$. Recently, air reduction has been performed as a primary treatment, because it has a shorter time for reduction, it is easier to conquer as it can give a constant pressure to the intussusceptum, and it has lesser risk for complications, such as perforation, compared to the use of barium contrast agent $[2,12]$. However, the absolute contraindication of this non-surgical reduction is the presence of free intraperitoneal air, possibility of peritonitis, and clinical instability; thus, surgical treatment is considered when a non-surgical reduction is likely to fail [12]. Koh et al. [13] reported that there is a higher likelihood of non-surgical reduction failure when the patient is younger than 6 months, time from the onset of symptoms to the time of non-surgical reduction was $>24$ hours, and the patient has hematochezia or lethargy. Stein et al. [14] reported that the predictors of air reduction failure is ileoileal colic intussusception, symptom duration of $>2.8$ days, rectal bleeding, and failure of barium reduction.

Even after successful non-surgical or surgical reduction, a recurrence of intussusception may appear, and the recurrence rate is reported to be approximately $4-14 \%[5,7,13,15-$ 18]. Table 1 summarizes the overall recurrence rate of intussusception and the recurrence rate according to each reduction method studied in various literature. There have been many studies that have evaluated the risk factors and predictors of recurrent intussusception. Among them, recurrence is more common in non-operative reduction cases 
Tae Gyoung Lee, et al.: Successful air reduction in a patient with recurrent intussusception

Table 1. Comparison of the recurrent rate of intussusception among studies in the literature

\begin{tabular}{|c|c|c|c|c|c|c|c|}
\hline \multirow{3}{*}{ Year } & \multirow{3}{*}{ Country } & \multirow{3}{*}{$\begin{array}{c}\text { Overall recurrent } \\
\text { rate (\%) }\end{array}$} & \multicolumn{5}{|c|}{ Recurrent rate after successful reduction (\%) } \\
\hline & & & \multirow{2}{*}{ Air reduction (\%) } & \multirow{2}{*}{$\begin{array}{l}\text { Barium reduction } \\
(\%)\end{array}$} & \multicolumn{3}{|c|}{ Operative treatment } \\
\hline & & & & & Manual reduction (\%) & Resection (\%) & Others (\%) \\
\hline 1975 & Canada [15] & $5-11$ & - & 11 & 3 & - & \\
\hline 1983 & Korea [5] & 7.1 & - & 23.0 & 2.3 & 0 & \\
\hline 1994 & United States [17] & 8.7 & 13.4 & - & 1 & 0 & \\
\hline 2005 & Korea [7] & 12.8 & - & 4 & 0 & - & \\
\hline 2006 & Taiwan [13] & 4 & - & - & 4.9 & 0 & lleopexy (4.3) \\
\hline 2010 & Thailand [16] & 8.0 & 11.4 & 15.8 & 3 & 0 & \\
\hline 2014 & United States [4] & 14.4 & 16.5 & - & 5 & 4 & \\
\hline
\end{tabular}

than in manual reduction cases [16. Ein [15] explained that the adhesions created by surgical manipulation of the intestine and appendectomy may reduce the recurrence rate after surgical reduction of an intussusception. Soper and Brown [19] reported that appendectomy performed simultaneously with surgery prevents the recurrence of intussusception as it results in additional bowel adhesion and bowel fixation. On the other hand, Cooke and Lewis [20] suggested that the cutting site of the appendix acts as a leading cause of intussusception, but this requires further investigation.

Intestinal resection for intussusception is known to eliminate the risk of recurrence. In fact, Park et al. [5] reported that the recurrence was observed in $12.0 \%$ of barium reduction cases and $2.3 \%$ of surgical reduction cases, but no recurrence was found after resection. Niramis et al. [16] and Champoux et al. [17] have suggested that there was no recurrent case after intestinal resection for intussusception. Koh et al. [13] reported a recurrence of $4.9 \%$ after surgery and $4.3 \%$ after ileopexy, but no recurrence was found after resection. The original intussusception caused spasm or edematous changes in some parts of the intestine, and by removing it through a resection of the intestinal tract, it prevents the recurrence of intussusception. In addition, the partial resection of the bowel loop in the large area to create adhesion of the bowel loop prevents intestinal movements that could cause intussusception. Besides, it is thought to reduce the risk of recurrence of intussusception by eliminating the leading lesion, i.e. polyps, diverticulum, ectopic glandular tissue, and band [15,19]. However, Fisher et al. [18] reported a recurrence in 2 (4\%) out of the 56 patients who underwent resection. Both cases were small bowel-small bowel intussusception, but there was no mention of treat- ment after relapse.

In the present case, the patient was diagnosed as having ileocolic intussusception with peritonitis at the age of 5 months, and surgical treatment was performed. The necrotic intestine was confirmed after manual reduction; thus, $10 \mathrm{~cm}$ resection of the distal ileum and $5 \mathrm{~cm}$ resection of the cecum as well as ileocolostomy were performed. At that time, no leading point of intussusception was found in the abdominal ultrasound imaging or during the surgical procedure. At 9 months postoperatively, he was brought to the emergency room due to hematochezia. Abdominal ultrasound examination showed ileocolic intussusception on the right upper abdomen. No other findings were seen, except for multiple mesenteric lymph nodes. After successful air reduction, we performed abdomen-pelvis $\mathrm{CT}$ to confirm the pathologic leading point, and found intestinal wall thickening at the anastomotic site adjacent to the surgical material and multiple mesenteric lymph nodes around the right common iliac artery. No other lesions could be considered as the pathologic lead. He is currently being followed up at our clinic and has been without any recurrence for three years.

Given that the recurrence of the same type of intussusception after intestinal resection for intussusception is rare, it is important to not delay the performance of abdominal ultrasonography or abdomen-pelvis CT to diagnose intussusception, especially in pediatric patients with symptoms suggestive of intussusception, such as irritability, abdominal pain, vomiting, or hematochezia, even if the patient had previously undergone intestinal resection for intussusception. We reported the case of recurrent intussusception with a history of ileocecectomy for ileocolic intussusception for 
the first time. We consider this case to be significant in in terms of its contribution to the literature.

\section{ACKNOWLEDGMENTS}

We thank Young Min Jo, Sung Bae Jeon for assistance with manuscript preparation.

\section{CONFLICT OF INTEREST}

No potential conflict of interest relevant to this article was reported.

\section{REFERENCES}

1. Lee KS, Park YJ. Clinical analysis of recurrent intussusception and the pathologic lead point in a single center. Korean J Pediatr Gastroenterol Nutr 2009;12:163-70.

2. Shin SH, Rho YI, Park YB, Moon KR. Clinical significance of repeated delayed air reduction in unsuccessful initial reduction of intussusception. Korean J Pediatr Gastroenterol Nutr 2001;4:175-80.

3. Ko KM, Song YW, Je BK, Han JJ, Woo CW, Choi BM, et al. Risk factors for the failure of non-operative reduction of intussusceptions. Korean J Pediatr Gastroenterol Nutr 2008;11:110-5.

4. Beres AL, Baird R, Fung E, Hsieh H, Abou-Khalil M, Ted Gerstle J. Comparative outcome analysis of the management of pediatric intussusception with or without surgical admission. J Pediatr Surg 2014;49:750-2.

5. Park SO, Seo IS, Seo JK, Park KW, Kim WK, Yeon KM. Recurrent intussusception in infancy and childhood. Seoul J Med 1983;24:106-15.

6. Yoo ES, Seo JW, Lee SJ. The risk factors related to recurrent intussusception by ultrasonography. J Korean Pediatr Soc 1996;39:1707-16.

7. Park BC, Kim SY, Jung SJ. A comparative analysis of clinical features and treatment outcomes of intussusception according to age distribution. Korean J Pediatr Gastroenterol Nutr
2005;8:150-6.

8. Hur NJ, Ryu MH, Lee DJ, Kwon JH. A clinical observation on children with transient small bowel intussusception. Korean J Pediatr Gastroenterol Nutr 2000;3:160-8.

9. Park MH, Shon SM, Choe BK, Kim YH, Lee HJ, Choi WJ, et al. A suggested new clinical classification for pediatric intussusception. Korean J Pediatr Gastroenterol Nutr 2006;9:3947.

10. Swischuk LE, Hayden CK, Boulden T. Intussusception: indications for ultrasonography and an explanation of the doughnut and pseudokidney signs. Pediatr Radiol 1985;15: 388-91.

11. del-Pozo G, Albillos JC, Tejedor D, Calero R, Rasero M, de-laCalle U, et al. Intussusception in children: current concepts in diagnosis and enema reduction. Radiographics 1999;19:299319.

12. Zheng JY, Frush DP, Guo JZ. Review of pneumatic reduction of intussusception: evolution not revolution. J Pediatr Surg 1994;29:93-7.

13. Koh CC, Sheu JC, Wang NL, Lee HC, Chang PY, Yeh ML. Recurrent ileocolic intussusception after different surgical procedures in children. Pediatr Surg Int 2006;22:725-8.

14. Stein M, Alton DJ, Daneman A. Pneumatic reduction of intussusception: 5-year experience. Radiology 1992;183:681-4.

15. Ein SH. Recurrent intussusception in children. J Pediatr Surg 1975;10:751-5.

16. Niramis R, Watanatittan S, Kruatrachue A, Anuntkosol M, Buranakitjaroen V, Rattanasuwan T, et al. Management of recurrent intussusception: nonoperative or operative reduction? J Pediatr Surg 2010;45:2175-80.

17. Champoux AN, Del Beccaro MA, Nazar-Stewart V. Recurrent intussusception. Risks and features. Arch Pediatr Adolesc Med 1994;148:474-8.

18. Fisher JG, Sparks EA, Turner CG, Klein JD, Pennington E, Khan FA, et al. Operative indications in recurrent ileocolic intussusception. J Pediatr Surg 2015;50:126-30.

19. Soper RT, Brown MJ. Recurrent acute intussusception in children. Arch Surg 1964;89:188-98.

20. Cooke DC, Lewis EC. A thirty-year survey of acute intussusception in childhood. Lancet 1960;276:1359-64. 